\title{
A Numerical Approach for Implementing Air Intakes in a Canard Type Aircraft for Engine Cooling Purposes
}

\author{
Odenir de Almeida1,* $\mathbb{D}$, Pedro Correa Souza ${ }^{1} \mathbb{D}$, Erick Cunha²
}

1.Universidade Federal de Uberlândia - Faculdade de Engenharia Mecânica - Centro de Pesquisa em Aerodinâmica Experimental - Uberlândia/MG - Brazil. 2.Fábrica Brasileira de Aeronaves - Uberlândia/MG - Brazil

*Corresponding author: odenir.almeida@ufu.br

\begin{abstract}
This work presents selected results of an unconventional aircraft development campaign. Engine installation at the rear part of the fuselage imposed design constraints for air intakes that should be used for cooling purposes. Trial and error flight tests increased the development cost and time which required a more sophisticated analysis through computational fluid dynamics (CFD) techniques and robust semiempirical approach. The carried-out investigation of the air intakes started with an empirical approach from guidelines for designing NACA and scoops. Numerical studies via computational fluid dynamics were performed with the air intakes installed in the aircraft fuselage. An analysis based on the air intake efficiency, drag and the effect of angle of attack are detailed in this work. Different air intakes designs, such as scoops of different shapes, were evaluated seeking for improved air intake efficiency and low drag while providing enough air for cooling the engine compartment. The results showed that the numerical approach used herein decreased the development cost and time of the aircraft, providing a reasonable low-cost approach and leading to a design selection more easily. Based on the current approach the canard airplane geometry was changed to account for the new selected air intake for engine cooling purposes.
\end{abstract}

Keywords: NACA; Scoop; Aerodynamic drag; Canard; CFD.

\section{INTRODUCTION}

Air intakes of different shapes and sizes are commonly used for several systems of an airplane, especially to provide fresh air for any air-breathing device or even for cooling down components. Examples of its applications are air conditioning system and ventilation of hydraulic and fuel lines as well as engine cooling inside its compartment. According to literature, Laruelle (2002), El-Sayed and Emeara (2016), among others, at least two types of air intakes are commonly seen: NACA air-intakes and scoop intakes. Often, these air intakes are also called auxiliary air intakes and can be applied to either receiving ram air for engine breathing or cooling it down, depending on the aircraft design. One very interesting view of the application of such air intakes is seen on canard-type aircrafts, which have in general the engine mounted in the rear part of the fuselage - pusher configuration - as seen on Fig. 1. Usually, canard aircrafts are motorized with jet engines for

Received: Mar. 25, 2020 | Accepted: Oct. 4, 2020

Peer Review History: Double Blind Peer Review

Section Editor: T. John Tharakan 
high speed and propellers for low-speed flight. In the class of propeller-driven airplanes, the engine cooling is a challenge due to the intake only rely on the ram air without the propeller slipstream. Also, internal flow drives the position of the intakes, as the air must pass through all cylinders in a transversal way if the engine is of the air-cooled type - Stalewski and Żółtak (2014).
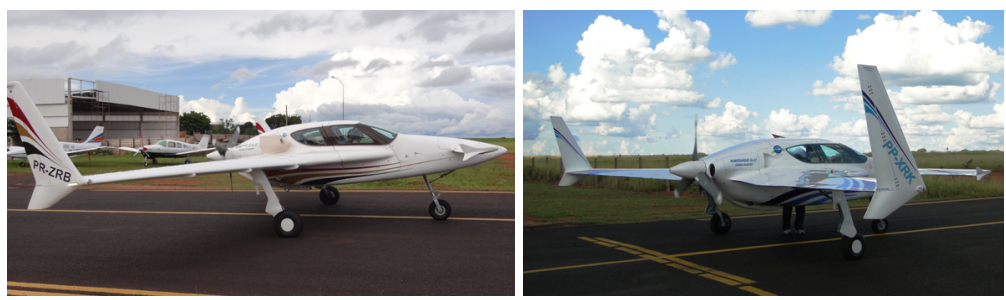

Figure 1. Typical canard-type aircraft. (Courtesy of FABE Ltd.).

The intake-type selection depends strongly on the design requirements imposed to the aircraft and is also related to the ambient conditions. In fact, during the aircraft design process different types of air-intakes should be considered, evaluated and compared, to achieve the main target to mass flow by minimally impacting the aircraft aerodynamics performance, especially in terms of drag penalty.

Since aerodynamic drag of an air-intake could not be neglected, the design selection must also account for it, associated as well as with mass flow rate, pressure recovery, water or ice-ingestion and structural loading and assembly. Some advantages are seen for NACA-type air-intakes since it has no external projections, as shown in Fig. 2, resulting in low aerodynamic drag and no requirements for specific structural reinforcements, causing no impact on the weight of aircraft. However, this type of air intake is generally less efficient than a scoop mainly due the difficulty to achieve higher dynamic pressure and flow volumes. Its operation is based on the combination of a diverging ramp and the curvature profile of the side walls which crates counter-rotating vortices, deflecting the boundary layer away from the inlet and promoting potential flow (Frick et al. 1945).

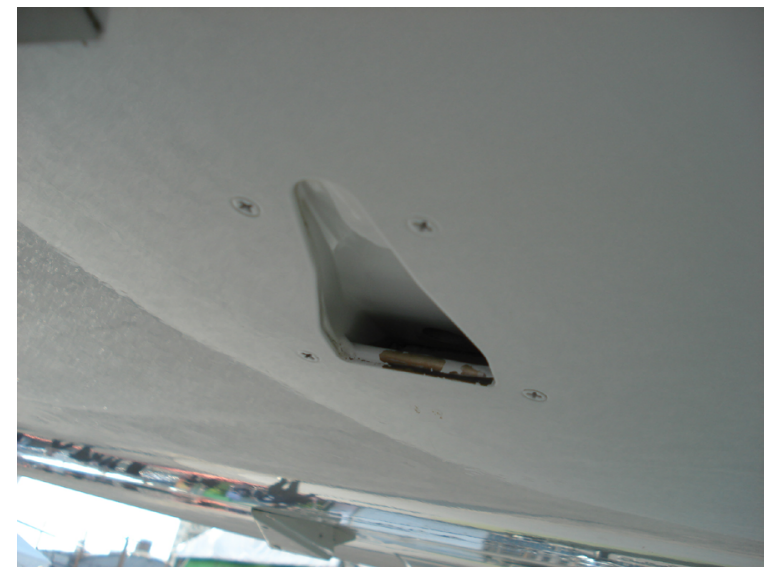

Figure 2. NACA-type air intake.

The other type of air-intake is the scoop, as illustrated in Fig. 3. Unlike a flush-air-intake, the scoop presents external projections designed to capture air outside the boundary layer, thereby recovering higher dynamic pressure and leading to a higher efficiency (Seddon and Goldsmith 1999). The major disadvantage of this type of installation is related to a drag penalty and the protuberance into the flow which impacts the aircraft weight and performance. Another disadvantage associated with ingestion of water, foreign objects and the formation of ice at the air entry must be highlighted (Faria and Oliveira 2002). 


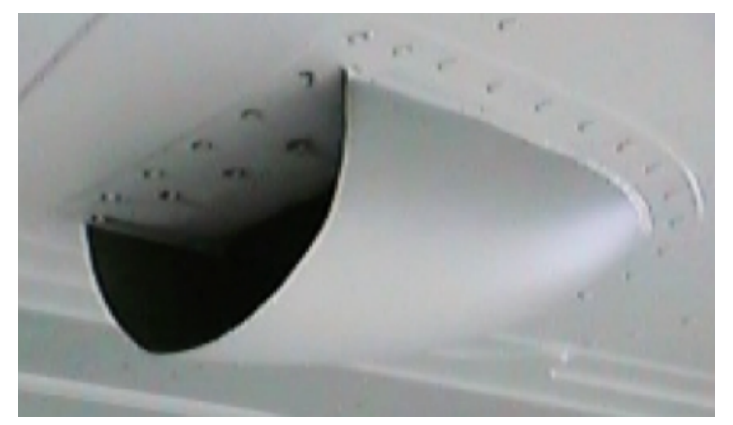

Figure 3. Scoop-type air intake.

Traditionally, at least three parameters are very important to look at to evaluate the performance of the air intakes: The first is the mass flow of air that enters the air-intake or, more precisely, the ratio between this mass flow and the theoretical mass flow that would be in the entrance under conditions of undisturbed flow; the second is the dynamic pressure recovery efficiency of the entry, which is defined as the ratio between the dynamic pressure in the throat of the intake and dynamic pressure in the undisturbed flow; the last one is the drag coefficient generated by the air-intake itself. To analyze all these parameters, a rational method must be available with satisfactory results and reasonable cost for industry. In this context, what is accessible related to the design of conventional air intakes is published in Engineering Sciences Data Unit (ESDU 2004). This database was based on experimental data which conclude that dynamic pressure recovery efficiency is strongly influenced by variations in mass flow. Also, increasing thickness of the boundary layer results in low efficiency while a uniform and continuous flow at the entrance of the throat is desirable for applicability. It is a semiempirical approach suitable for a preliminary air intake design, according to Rütten et al. (2009).

On the other hand, most of recent studies involving application of air-intakes for the aeronautical industry use computational fluid dynamics (CFD) techniques for the analysis and selection (Taskinoglu and Knight 2003). For instance, Shams and Masud (2015) presented a numerical analysis of NACA flush-intakes at high sub- and supersonic free stream Mach numbers. In their work, a comparison of different turbulence models was performed showing the effect of the turbulence modeling in quantities like mass flow rate and total pressure recovery. The work of Liu et al. (2013) also applied CFD simulations to analyze the flow characteristics in the engine compartment of a light aircraft. A complete model was used with air intake, air duct, guide vane, and air outlet were designed. The conceptual design decision was taken by considering only the CFD results with no experimental validation. Stalewski and Żółtak (2014) presented a preliminary design of the air-intake system in a small propeller aircraft by means of a parametric study involving in-house software for modeling the aircraft and CFD coupled with a virtual blade model. The air-intake system was analyzed taking into account pressure losses, quality of air stream and effectiveness of particles separator installed in the turboprop engine. Different airintake types for bleed less aircrafts were evaluated by Rütten et al. (2009) trying to come up with a methodology for comparing the efficiency of such intakes and their impacts on the overall aircraft performance. The analysis was performed through CFD calculations. Another interesting work is given by Koch et al. (2015), who developed an experimental study on the effect of boundary layer ingestion into highly integrated intakes. Due to the circular shape of the air intake, the performance was discussed in terms of circumferential distortions and total pressure recovery. The work of Pignier et al. (2016) presented an aerodynamic and aeroacoustics analysis of submerged air intakes at low Mach numbers. In this study, a focus was given to the flow dynamics and the noise characteristics, showing the capabilities of the numerical methods applied to solve the coupled problem - aerodynamics and acoustics.

For the general aircraft market comprising small airplanes, such as canard-type, only few works are presented in the open literature regarding this subject. In this case, the implementation of such air-intake is based on experience and simpler design rules with low cost and time, since financial resources are stricter for this class of aircraft manufacturers. By considering such fact, one of the goals of this research is to analyze the variation of the air-intake efficiency, using CFD for obtaining results that allow the selection of an air intake with minimum aircraft performance penalty and good cooling characteristics for the engine compartment, while reducing the trial and error flight-test cost and time. To achieve this, a set of numerical studies were performed with different shapes of air intakes mounted on the aircraft fuselage. These simulations were performed using Reynolds-averaged 
Navier-Stokes (RANS) simulations by means of shear stress transport (k- $\omega$ SST) turbulence model. An analysis based on the air intakes efficiency, drag and the effect of angle of attack (flow field pattern) are detailed in the results section achieving considerable reduction in the development time and cost and leading to a design selection more easily.

\section{CASE-STUDY DESCRIPTION}

The case study is a canard-type aircraft named Bumerangue EX-27 Cross-country in the general aviation category (experimental aircraft). This is a four-place aircraft, monoplane, single engine installed in the pusher configuration, with retractable landing gear. The powerplant system is composed by a Continental TSIO 360 EB Turbo - air refrigerated developing $210 \mathrm{HP}$ at $2700 \mathrm{rpm}$ and equipped with a MT propeller with stainless steel protection and fiberglass. Due to its geometric configuration, this type of aircraft has a piston engine mounted in a pusher configuration in the rear part, behind the cabin, which needs cooling during flight. Figure 4 provides a general view about the Bumerangue EX-27 Crosscountry aircraft.
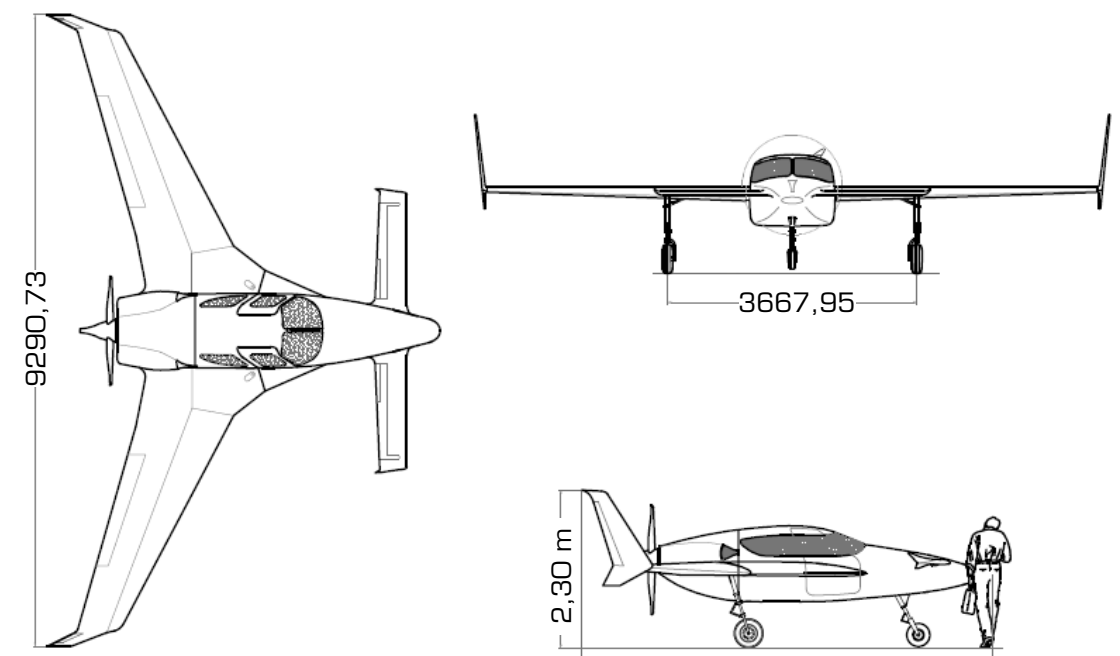

Figure 4. Bumerangue EX-27 Cross-Country (Courtesy of FABE Ltd.).

During the test-development campaign of this aircraft, the need to reduce the temperature inside the engine compartment was identified. Figure 5 illustrates one of the flight tests where wool tufts were applied to visualize the flow in region of the air admission for the engine. Quality of figure was restricted to the resolution of the camera taken on-board (on wing) at the time of the flight-test campaign.

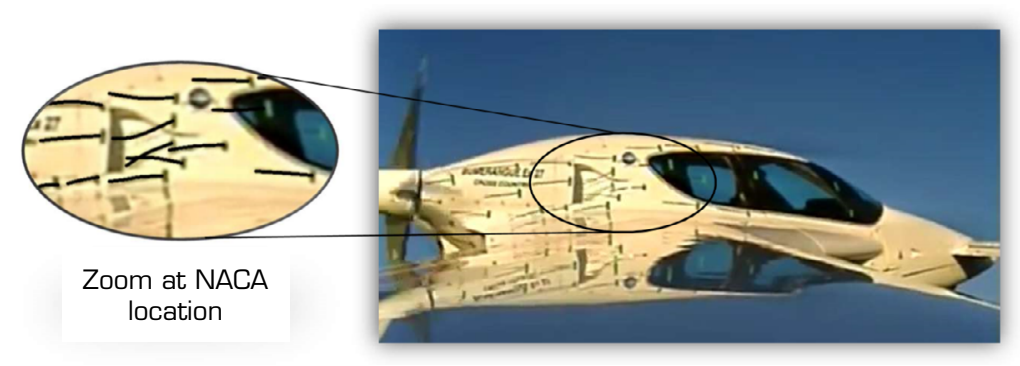

Figure 5. Wool tufts visualization - flight-test at 3,000 ft with 120 knots (courtesy of FABE Ltd.). 
To provide the necessary air flow for preventing the engine overheating, three new air intakes were designed in addition to the existing one, called "standard" from this point forward (Figs. 6 and 7). According to Fig. 6, circular and semicircular scoops were designed. Figure 7 shows the description of the air intake NACA-type. The standard air intake was considered at early stages of the flight-test development campaign to avoid any engine overheating and, consequently, damage of the propulsion system. The details about the dimensions used to create the circular, elliptic and NACA air intakes are showed in the next section.

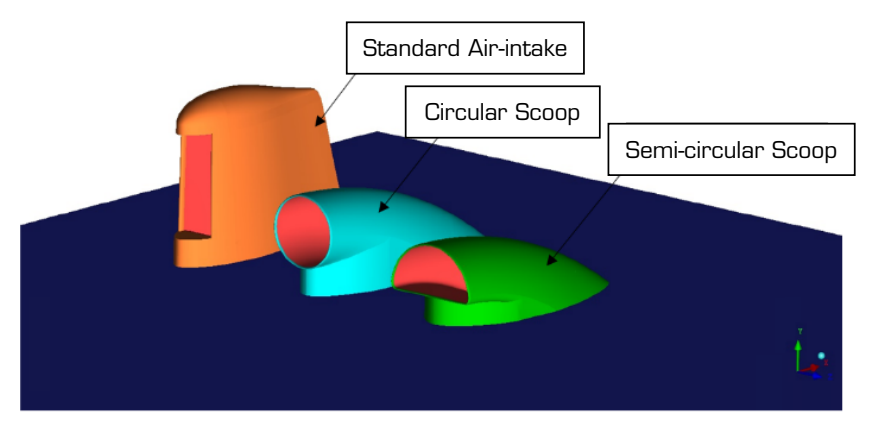

Figure 6. Overall description of air intakes.

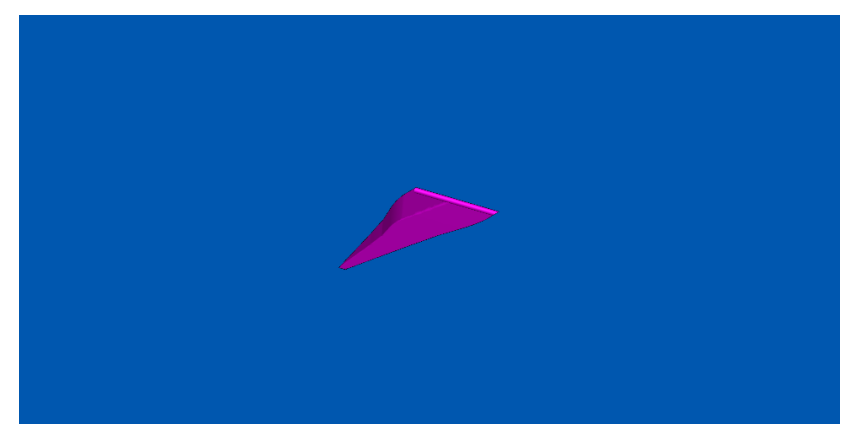

Figure 7. Overall description of the NACA-type air intake.

\section{SEMIEMPIRICAL MODELING}

Previous calculations for sizing a NACA air intake for the airplane have been performed with the use of a well-known semiempirical method (ESDU 2004). The following sections describe the calculations done by each air intake evaluated.

\section{NACA air intake}

To predict and calculate the parameters from the flush intake (NACA), this semiempirical method utilizes a catalogued database to compute the drag and pressure recovery of small auxiliary air intakes totally or partially immersed in the boundary layer (Fig. 8). This approach is suitable at subsonic speeds. Essentially, the theory of two-dimensional boundary-layer calculation is used as reference and modified in the light of the available experimental data.

The flight test was carried out at two specific angle-of-attack (AOA) conditions in a nonstandard atmosphere, which resulted in an international standard atmosphere (ISA) $+16^{\circ} \mathrm{C}$. Table 1 summarizes these specific conditions: a) cruise condition at $2^{\circ} \mathrm{AOA}$; b) critical condition at $15^{\circ} \mathrm{AOA}$, emulating a take-off flight path. 


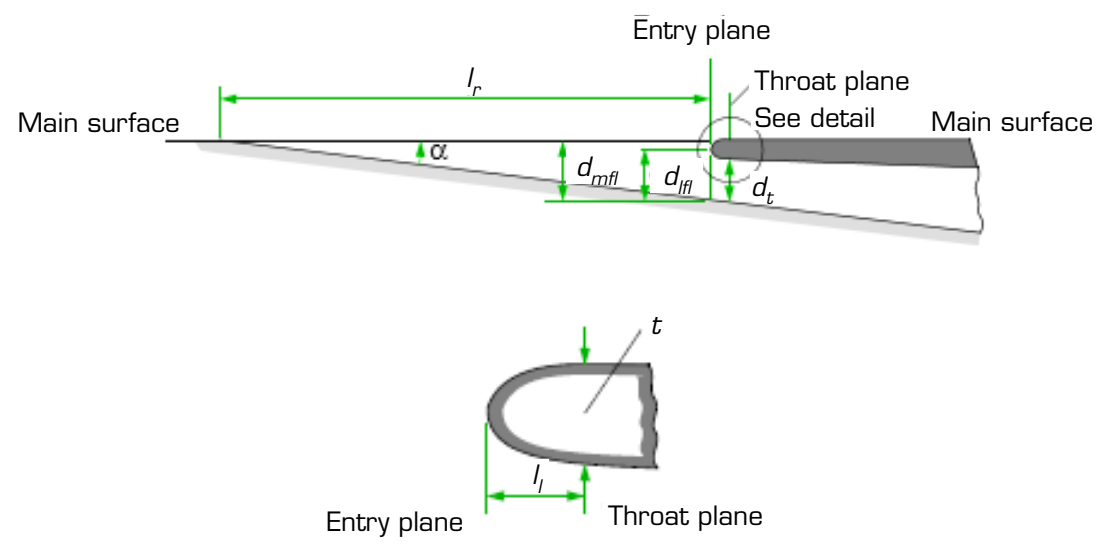

Figure 8. Geometric parameters for flush intake (NACA), after ESDU (2004).

Table 1. Design operational condition (ISA $\left.+16^{\circ} \mathrm{C}\right)$.

\begin{tabular}{cc}
\hline Parameters & Operational Condition \\
\hline Speed & 122 knots $(61.73 \mathrm{~m} / \mathrm{s})$ \\
\hline Angle of Attack & $2^{\circ}$ and $15^{\circ}$ \\
\hline Altitude & $3,000 \mathrm{ft}(914.4 \mathrm{~m})$ \\
\hline Temperature & $25^{\circ} \mathrm{C}$ \\
\hline Density & $1.211 \mathrm{~kg} / \mathrm{m}^{3}$ \\
\hline Pressure & $90,812 \mathrm{~Pa}$ \\
\hline
\end{tabular}

According to the manufacturer (FABE Ltd.).

Using the ESDU with the objective of corroborating the further CFD calculation, the following variables are given with their respective values in Table 2, which are the mass flow, the boundary-layer thickness and the boundary-layer momentum thickness, considering also the throat aspect ratio and a ramp angle. This NACA parameters leads to the minimum size of the flush intake to provide air to the engine, based on the engine cooling requirements specified by the engine manufacturer.

Before proceeding with the theoretical calculation, it is important to note that some evaluated data were taken from specific figures from ESDU database. These figures will not be reproduced herein; for brevity, results will be shown to the main parameters in the database computation. The reader should go for details in ESDU (2004).

A set of calculation using ESDU led to resizing the original design. At the operational condition of the airplane, the new mass flow has been targeted to $0.060 \mathrm{slug} / \mathrm{s}$ after a more detailed analysis and data verification with the engine manufacturer. By applying the calculation procedure, guided within ESDU (2004), the values found were listed below:

Table 2. Flush intake design parameters.

\begin{tabular}{cc}
\hline ESDU parameters & Units \\
\hline$m$ & $0.060 \mathrm{slug} / \mathrm{s}^{\star}$ \\
\hline$\delta_{h}$ & $0.1 \mathrm{ft}$ \\
\hline$\theta_{0}$ & $0.01 \mathrm{ft}$ \\
\hline$\alpha_{\mathrm{ramp}}$ & $7^{\circ}$ \\
\hline$w / d t$ & 4 \\
\hline
\end{tabular}

*According to cooling flow. 


$$
\begin{gathered}
d_{t}=0.060 \mathrm{~m} \\
\mathrm{w}=d_{t} \times 4=0.24 \mathrm{~m} \\
\mathrm{l}=\mathrm{t}=0.25 \cdot d_{t}=0.015 \mathrm{~m}
\end{gathered}
$$

The maximum external height of the intake, $d_{m f l}$ and the lip highlight height, $d_{1 f l}$, determined in the intake plane relative to the ramp floor, are calculated by Eqs. 1 and 2:

$$
\begin{gathered}
d_{m f l}=d_{t}+t-l_{l} \tan \alpha=0.073 \mathrm{~m} \\
d_{1 f l}=d_{t}+0.5 t-l_{l} \tan \alpha=0.065 \mathrm{~m}
\end{gathered}
$$

with a mass flow ratio of $m_{T} / m_{0} \approx 0.89$.

By following this procedure, the new NACA air intake design was targeted to mass flow instead of designing it for maximum efficiency. With the intake dimensions determined, the calculation of the drag coefficient for the flush intake $C_{D f l}$ and ram pressure efficiency $\mathrm{h}_{f l}$ proceeded in an identical manner to that set out in Silveira et al. (2017). The values are summarized below:

$$
\begin{gathered}
C_{D f l}=1.328 \\
\eta_{f l}=0.727
\end{gathered}
$$

Therefore, using this tabulated semiempirical approach, it was possible to obtain the parameters for designing a new flush intake (NACA), whose final dimensions are specified in Fig. 11.

\section{Scoop air intake}

The calculation procedure, as described in ESDU (2004), has been applied to define the scoop intake designed for full mass flow, as prescribed in Table 2. According to the theoretical approach, the scoop sizing led to the following values, according to the geometric parameters in Fig. 9:

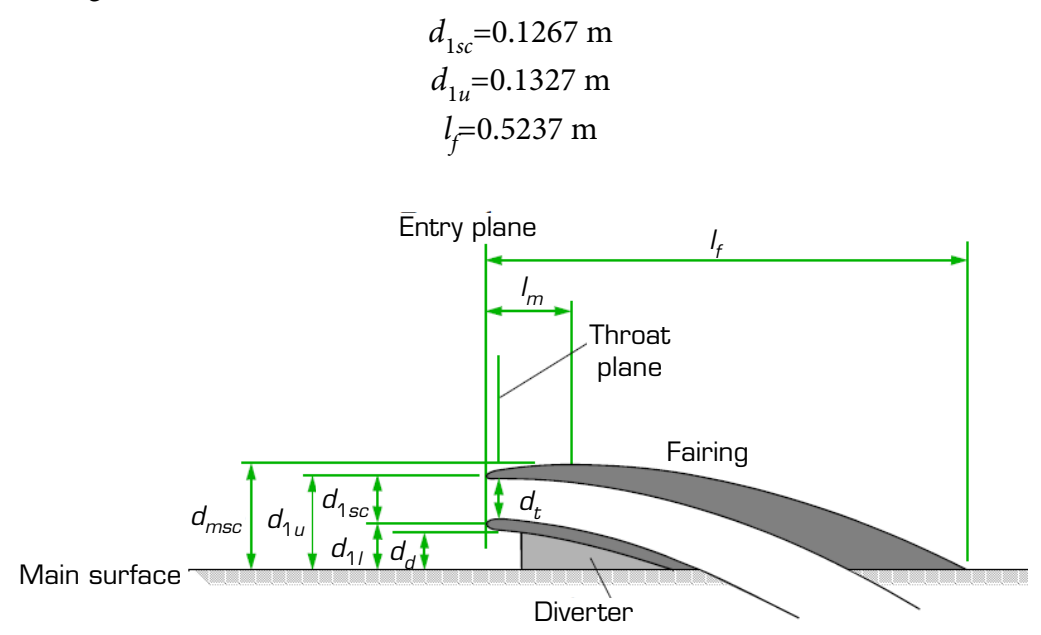

Figure 9. Geometric parameters for scoop intakes, after ESDU (2004).

By following this procedure, the scoop intake was targeted to mass flow instead of designing it for maximum efficiency. With the intake dimensions determined, the calculation of the drag coefficient for the scoop $C_{D s c}$ and ram pressure efficiency $h_{s c}$ proceeded. The values are summarized below:

$$
\begin{gathered}
C_{D s c}=2.074 \\
\eta_{s c}=0.99
\end{gathered}
$$




\section{Standard and elliptic air intake}

The additional standard and elliptic air intakes were designed respecting the mass flow rate by changing the entry area and by adding fairings to final assembly. As shown in Figs. 10, 11 and 12, except for the standard intake, the elliptic drawing is a geometric adjustment of the circular scoop intake as described by the semi-empirical method. The standard air intake was a previous design manufactured by the FABE Ltd., as previously mentioned, to avoid any damage for the engine during initial flight-test campaign.
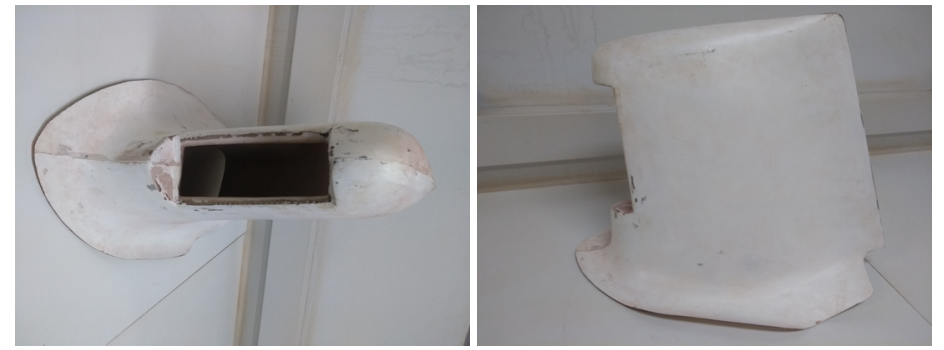

Figure 10. Standard air intake (Courtesy of FABE Ltd.).

(a)
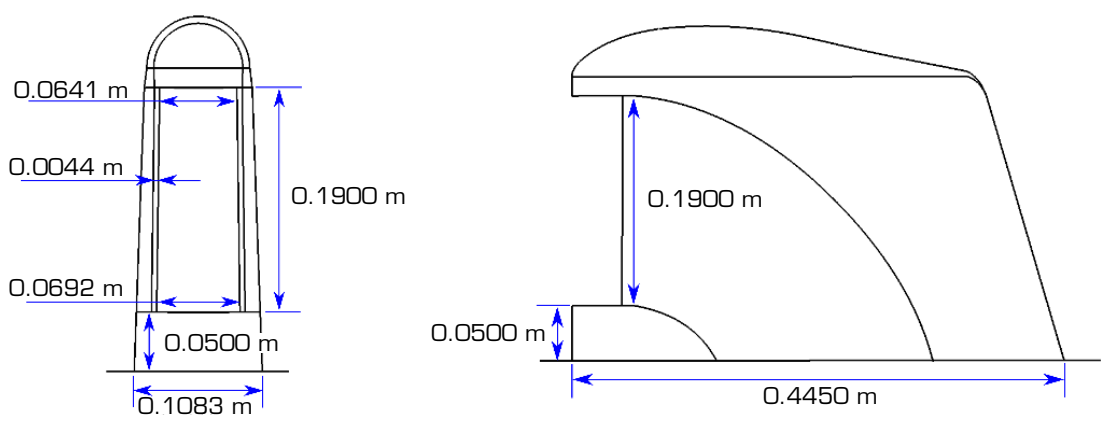

(b)

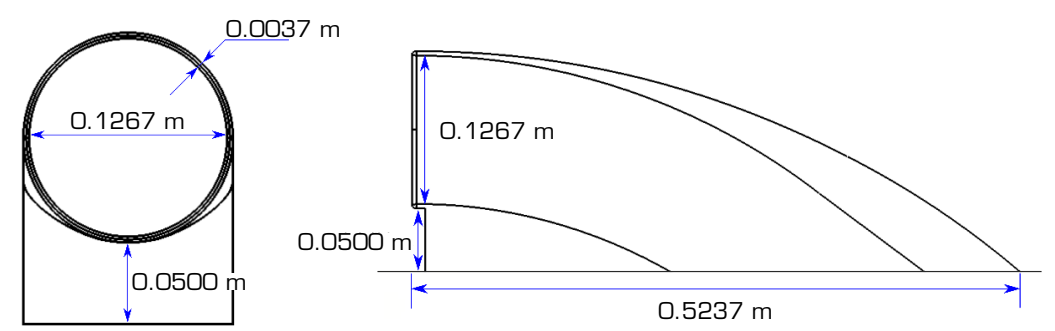

Figure 11. Geometric parameters for air intake; (a) standard; (b) circular scoop.

\section{NUMERICAL APPROACH}

A Reynolds-averaged Navier-Stokes (RANS) approach was used in this work as a design tool and selection for the best suited air intakes for engine cooling in a canard-type aircraft. The incompressible steady-state equations of motion were solved for several different three-dimensional domains involving the canard airplane and its air intakes. The governing equations were solved with a second order accuracy through a finite volume formulation employed by the METACOMP CFD++ software. 
(a)
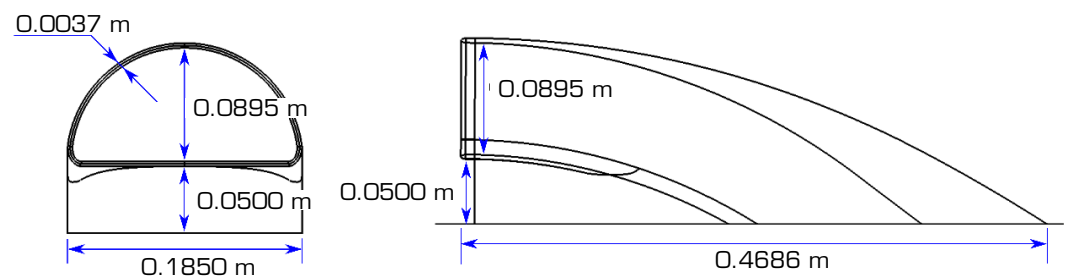

(b)

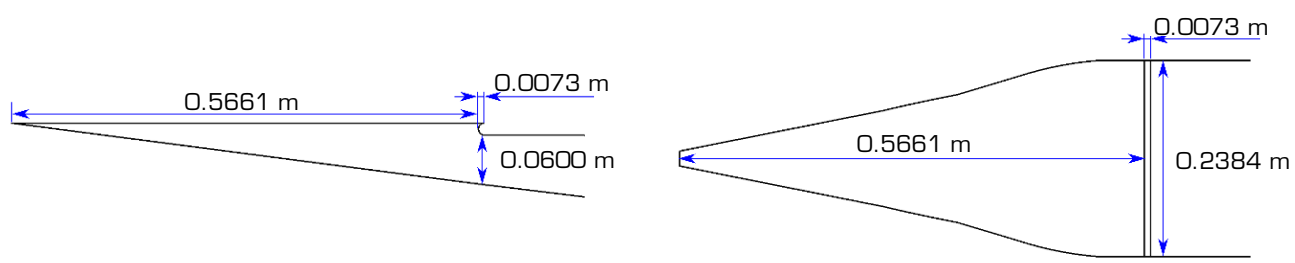

Figure 12. Geometric parameters for air intake. air intake; (a) Semicicular scoop (b) NACA.

\section{Turbulence modeling}

Due to the expected flow pattern over the airplane which exhibits regions of detachments and locations of strong pressure gradients, a turbulence model suited for this class of problem has been chosen. For the turbulence modeling, the k- $\omega$ SST (Menter 1993) turbulence model was applied, based on experiences acquired in the past works with RANS equations applied to external flows with boundary layer detachment. The $\mathrm{k}-\omega$ SST model is a turbulence closure comprising a transport equation for the turbulent kinetic energy $(\mathrm{k})$ and specific turbulence dissipation rate $(\omega)$. This model seems to provide reasonable results for external aerodynamics analysis and have been well documented in literature (Menter 1993; 1994). The RANS equations in conservation form for an incompressible fluid are presented in Eqs. 3 and 4 (Wilcox 1998).

$$
\begin{gathered}
\frac{\partial U_{i}}{\partial x_{i}}=0 \\
\rho \frac{\partial}{\partial x_{j}}\left(U_{i} U_{j}\right)=-\frac{\partial P}{\partial x_{i}}+\frac{\partial}{\partial x_{j}}\left(2 \mu S_{i j}-\rho \overline{u_{\imath}^{\prime} u_{\jmath}^{\prime}}\right)
\end{gathered}
$$

where $S_{i j}$ is the mean strain-rate tensor showed in Eq. 5.

$$
S_{i j}=\frac{1}{2}\left(\frac{\partial U_{i}}{\partial x_{j}}+\frac{\partial U_{j}}{\partial x_{i}}\right)
$$

The turbulence kinetic energy $(k)$ is shown in Eq. 6 and the Eddy viscosity is defined in Eq. 7.

$$
\begin{gathered}
\tau_{i j} \frac{\partial u_{i}}{\partial x_{j}}-\beta^{*} \rho k \omega+\frac{\partial}{\partial x_{j}}\left[\left(v+\sigma_{k} \mu_{T}\right) \frac{\partial k}{\partial x_{j}}\right]=0 \\
v_{t}=\frac{a_{1} k}{\max \left(a_{1} \omega, \Omega F_{2}\right)}
\end{gathered}
$$

The specific turbulent kinetic energy dissipation rate $(\omega)$ is defined in Eq. 8.

$$
\frac{\Upsilon}{v_{t}} \tau_{i j} \frac{\partial u_{i}}{\partial x_{j}}-\beta^{*} \rho \omega^{2}+\frac{\partial}{\partial x_{j}}\left[\left(\mu+\sigma_{k} \mu_{T}\right) \frac{\partial \omega}{\partial x_{j}}\right]+2\left(1-F_{1}\right) \rho \sigma_{\omega^{2}} \frac{1}{\omega} \frac{\partial k}{\partial x_{j}} \frac{\partial \omega}{\partial x_{j}}=0
$$


For brevity, the additional model functions and description such as $F_{1}, C D_{k w}, \tau_{i j}, \gamma_{1}$, $\phi$ and the coefficients of the k- $\omega$ SST turbulence model are not presented here. More details about these parameters could be found in Wilcox (1998), as well as Metacomp Technologies (2014).

The complete system of equations was solved by the CFD code in a three-dimensional domain with second order accuracy by running 3,000 iterations and until the residues fall 5 orders of magnitude. Further details about the domain and the meshes used in this work are described in the subsequent sections.

\section{Computational domain and boundary conditions}

The computational domain used is a hemisphere of radius equal to 50.5 times the length of the aircraft. Figure 13 illustrates this domain, out of scale for better viewing.

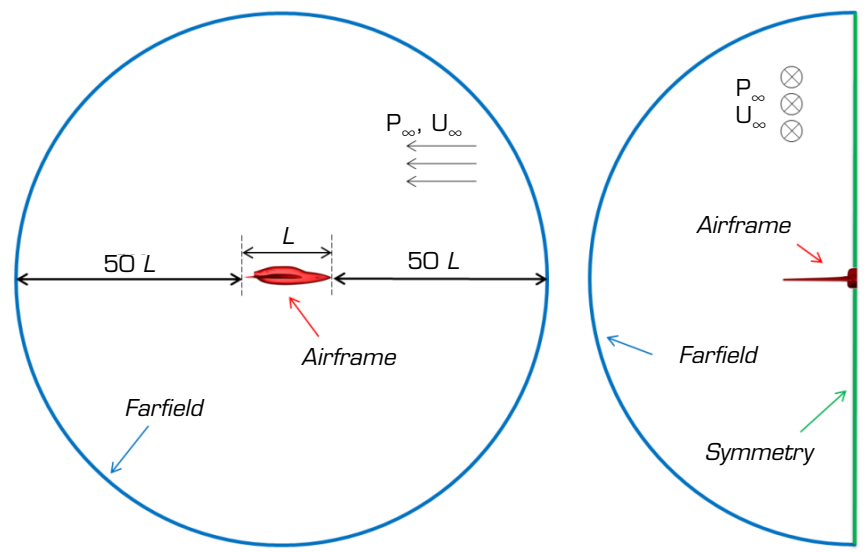

Figure 13. Front and side views of the computational domain used (out of scale).

The domain size was based on preliminary testing and similar works (Faria and Oliveira 2002). The boundary conditions applied considering all solid surfaces for the entire airplane, a so-called free stream (far field) was used in the hemisphere portion of the domain, where flow velocity (axially) as described in Table 1. As a half-domain simulation, the symmetry condition was considered in the mid-plane of the aircraft fuselage. The sizing of the computational domain as well as the boundary conditions have been adjusted based on previous experiences as described by Silveira et al. (2017) and Almeida and Souza (2017).

\section{Computational mesh}

The mesh used was an unstructured tetrahedral with prisms surrounding the fuselage, aiming at a good characterization of the boundary layer. Using Ansys IcemCFD software, the mesh was generated and had approximately 9 million elements for all geometries proposed. A prism layer covers all the walls assuring a y+ value of 30. A mesh illustration is presented in Fig. 14. As illustrated, volumetric control by means of density regions were used near the air intakes to refine the mesh locally and to guarantee a better result. Previous meshes with 3 and 6 million elements were considered as a mesh refinement study. By considering the stabilization of the drag value for the NACA airintake calculation, it was achieved with the 9 million elements and the mesh parameters were extended to the other air-intake geometries.

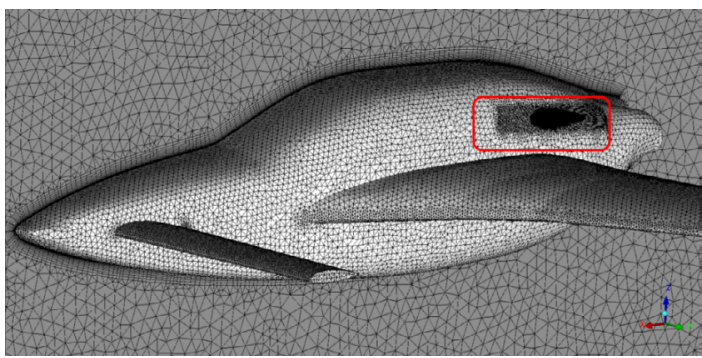

Figure 14. Mesh view, highlighting portion with the air-intake geometry. 
Keeping the mesh parameters constant for the whole domain, only the highlighted portion in Fig. 14 had spatial and discretization variation according to the simulated case. Figure 15 shows in detail the mesh generated in this region for each of the proposed cases. It is also important to say that to simulate boundary layers in turbulent flow requires fine grid spacing near the walls, closely dependent on the choice of the turbulence model (Chitale et al. 2014). In this work, the wall modeling was assumed as a tradeoff between computational resource available and reliability on the results leading to the requirement that the first cell height was beyond the viscous sublayer and into the log-layer or overlap region (y+ 30). In such a way, it was possible to assure that the results were asymptotically converged for drag values (DCd between the configurations) and are expected to be in accordance with other works in literature such as Jongen (1992), Knopp (2006) and Chitale et al. (2014) among others, at the time of this research.

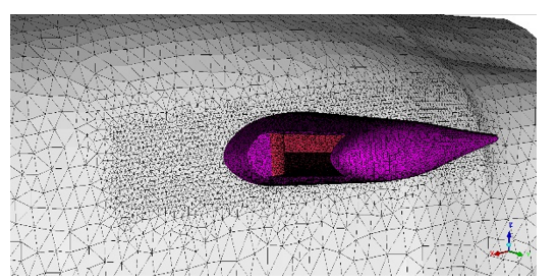

Standard

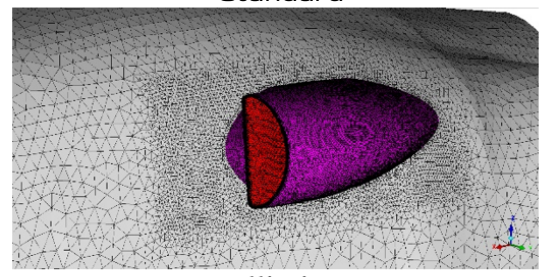

Elliptic

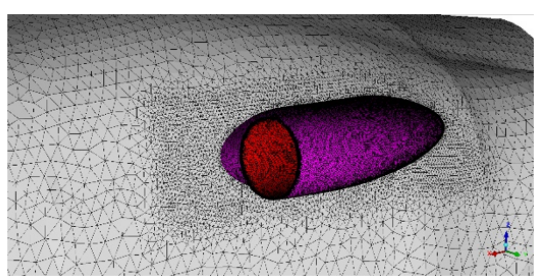

Circular

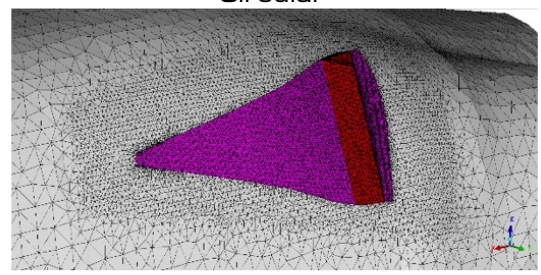

NACA

Figure 15. Mesh details for each air intake geometry.

The next section shows the results obtained with the RANS simulations of these four air-intake geometries at two different angle-of-attack conditions: $\left(\mathrm{AOA}=\alpha=2^{\circ}\right)$ at cruise condition and $\left(\mathrm{AOA}=\alpha=15^{\circ}\right)$ emulating take-off condition. The results are evaluated in terms of air intakes efficiency, drag, and the effect of the angle of attack $\alpha$.

\section{RESULTS}

With the purpose of solving this engine cooling problem for a canard-type aircraft, a good air-intake design is achieved when the air flow that enters the intake is enough to keep the engine cooled in any flight condition, with a minimal drag addition and maximum efficiency. Aiming those conditions, the previous geometries and conditions where simulated. As a designing and selection engineering tool, absolute values were not recorded in this work, but rather the difference between them.

\section{Effect of $\alpha$ (angle of attack)}

To analyze the global effect of $\alpha$ in the flow and to prevent repetitive results, initially the simulations in the following section present only the standard intake. The angles of attack of $2^{\circ}$ and $15^{\circ}$ where tested and Fig. 16 shows the symmetry plane with velocity streamlines for these conditions. 
(a)

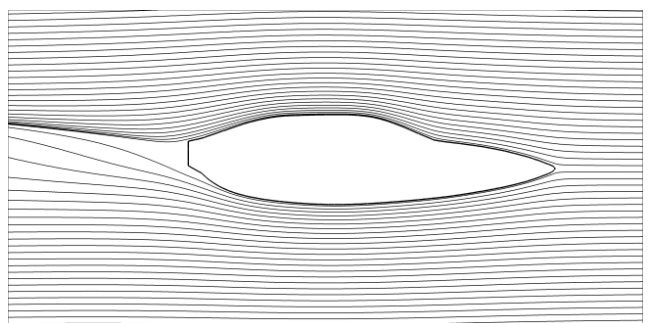

(b)

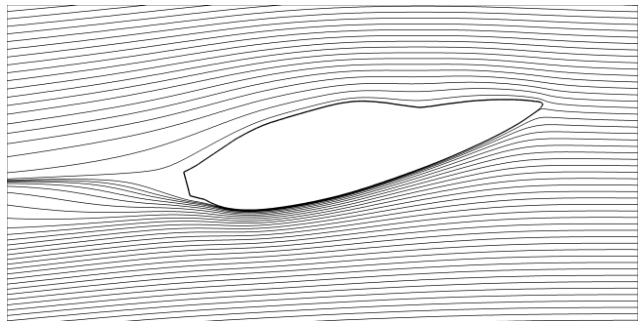

Figure 16. Streamlines in the symmetry plane for (a) $\alpha=2^{\circ}$, (b) $\alpha=15^{\circ}-$ standard air intake.

It is possible to see in Fig. 16 that the flow changes dramatically over the region of the air intake with a change in the AOA. With the increase of the AOA, it is expected that the air intake will be subjected to a more disturbed flow upstream, which can compromise its efficiency. To check this effect, Fig. 17 shows the increase in turbulent kinetic energy ( $k$ ) for the simulated angles a, presenting a sudden augmentation in the flow turbulence along the canard, the main wing (due to separation) and the region of the air intake. What is interesting to observe in Fig. 17 is that, despite the increase in flow turbulence in the canard and the wing, this effect is not perceived by the air intake, since there are no disturbances being carried to the air inlet.

(a)

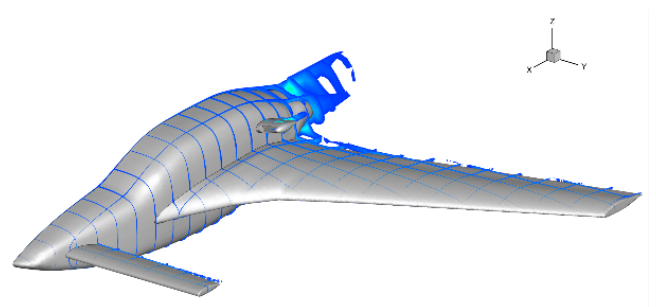

(b)

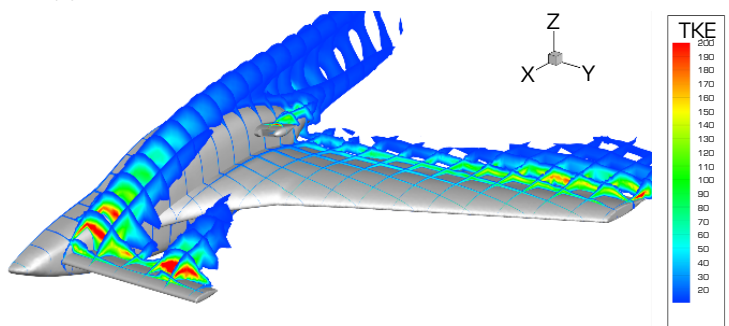

Figure 17. Turbulent kinetic energy (k) for (a) $\alpha=2^{\circ}$, (b) $\alpha=15^{\circ}$.

Besides the expected increase in lift, drag and turbulent kinetic energy in the take-off emulation condition, it is highly important to know the changes in the flow that is being diverted to the air intakes. Figure 18 shows the velocity streamlines entering the standard air intake in the two test-cases for (a). It is important to observe that the air flow that entries the intake comes from completely different regions as the angle of attack changes from $2^{\circ}$ to $15^{\circ}$. At the low AOA, the flow that arrives at the air intake follows the fuselage and it is almost aligned without major changes in its direction. The air intake at this flight condition is receiving almost undisturbed flow and it is expected to have higher efficiency. For the takeoff condition at $15^{\circ}$, it is possible to see that the upcoming flow is being diverted by the canard and reaches the entry of the air intake with little disturbance. Surprisingly, the canard does not affect negatively the flow and it is also expected that even at this higher AOA the air-intake efficiency must be high enough. It is important to say that this trend is seen in the other simulation results for the other air intakes.

(a)

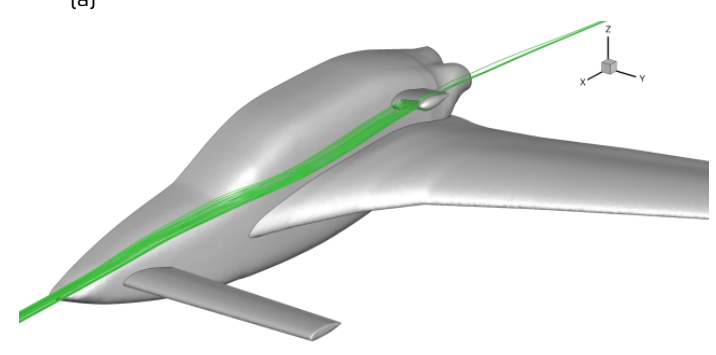

(b)

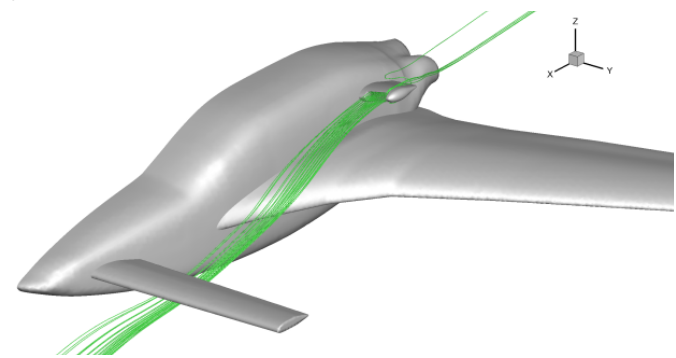

Figure 18. Streamlines entering the standard air intake for (a) $\alpha=2^{\circ}$, (b) $\alpha=15^{\circ}$. 
A close look at Fig. 19 shows the velocity streamlines that entry each of the intake geometries proposed. Due to similarity in the results for the flow field in that region, for AOA $2^{\circ}$ and $15^{\circ}$, only $\alpha=2^{\circ}$ is shown in Fig. 19.

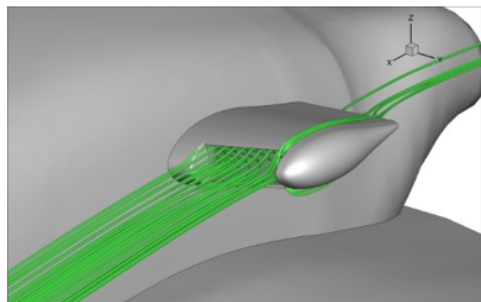

Standard

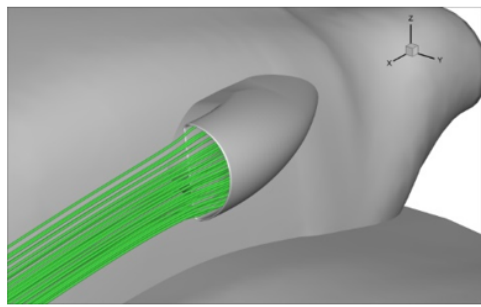

Elliptic

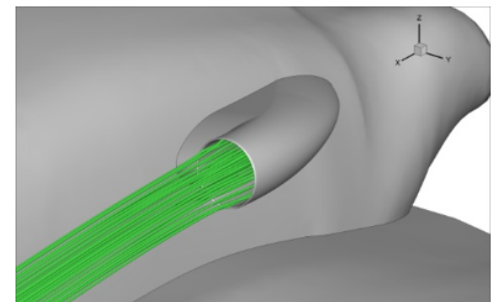

Circular

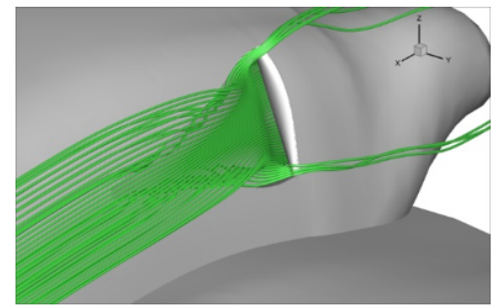

NACA

Figure 19. Streamlines for $\alpha=2^{\circ}$ entering the different air intake geometries.

Figure 19 reveals that some streamlines that comes out of the intake throat can be notice in the standard and NACA geometries, what is called the "spillage" of the air intake. This flow pattern indicates that the air is being spilled out and, therefore, not all its area is useful with consequently reduction in the air-intake efficiency and increase in the drag. Also, it is interesting to observe that both circular and elliptic air intakes are completely receiving undisturbed air flow, without showing any spillage, and, therefore, it is expected to have more efficiency that the others ones. Although the velocity streamlines for both a look alike, the dynamic pressure contour in the intake throats on Fig. 20 show some differences. These differences are in accordance with the flow field analysis performed, which were useful to better understand and to verify the influence of the angle of attack and the canard on the air intakes.
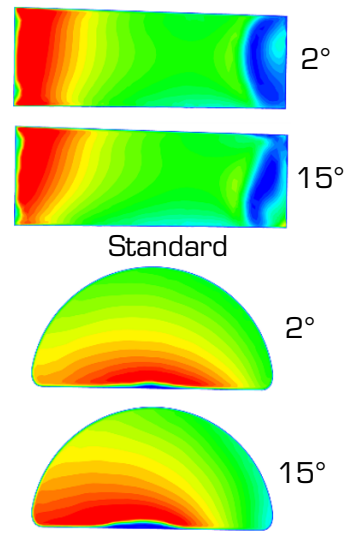

Elliptic

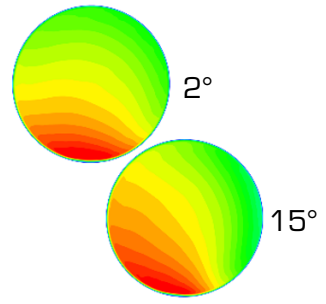

Circular

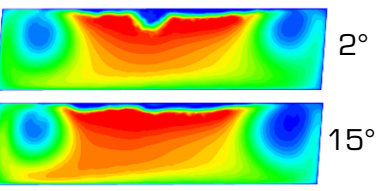

NĀCA

Figure 20. Dynamic pressure contour (Pd) on intakes throat. 


\section{Air intake efficiency}

The efficiency of an air intake is given by the relationship between the dynamic pressure at the throat and the dynamic pressure at infinity (free stream), so-called ram recovery ratio or pressure recovery, noted $\mathrm{h}$ in this paper and defined in Eq. 9:

$$
\eta=\frac{P_{T, 1}-P_{0}}{P_{T, 0}-P_{0}}=\frac{P_{d}}{P_{d \infty}}
$$

where $P_{T, 1}$ and $P_{T, 0}$ are the total pressures, $P_{T, 1}$ measured at the duct entrance (cross-sectional plane) and $P_{T, 0}$ at the far field, respectively. $P_{0}$ is the static pressure of the free stream.

According to El-Sayed and Emeara (2016), the pressure recovery depends on a wide variety of factors, including the shape of the inlet, the speed of the aircraft, the airflow demands of the engine, and aircraft maneuvers.

Thus, the contours of dynamic pressure considered at the duct entrance plane for each air intake is illustrated in Fig. 20 for the two AOAs $\left(\alpha=2^{\circ}\right.$ and $\alpha=15^{\circ}$ ), as previously discussed. Regions of low dynamic pressure are mainly associated to losses into the flow such as vortices being generated by the presence of the air intake as well as flow boundary-layer separation in the duct, mainly at higher angles of attack. As seen in Fig. 20, the presence of these regions of low dynamic pressure are clearly observed for the standard and NACA air intakes, as well as in the bottom part of the elliptic intake.

By taking averaged-values of dynamic pressure (Pd) in the intakes throat (integration of node values at the cross-sectional area) and its value far away from the aircraft (far field), it is possible to calculate the intake efficiency from Eq. 9. These results are shown in Table 3.

Table 3. Mean dynamic pressure $(\mathrm{Pd})$ in $[\mathrm{Pa}]^{*}$ and ram recovery ratio $(\mathrm{h})$.

\begin{tabular}{ccccc}
\hline$\alpha$ & Standard & Circular & Elliptic & NACA \\
\hline $2^{\circ}$ & 1472.677 & 1802.407 & 1760.950 & 1472.388 \\
\hline $\mathrm{h}\left(2^{\circ}\right)$ & 0.64 & 0.78 & 0.76 & 0.64 \\
\hline $15^{\circ}$ & 1441.436 & 1835.240 & 1804.893 & 1537.987 \\
\hline $\mathrm{h}\left(15^{\circ}\right)$ & 0.62 & 0.79 & 0.78 & 0.67 \\
\hline * Measured at the intake throat. & & &
\end{tabular}

By analyzing Table 3, it is possible to conclude that the circular and elliptic intakes have the highest efficiency (closer to unity), and that the angle a does not modify the results substantially. It is important to remember that the uniformity of results over the flight conditions is desirable for this class of problem, assuring right flow through the engine compartment (El-Sayed and Emeara 2016; Rütten et al. 2013). Great changes in efficiency could mean that the intake is wrongly placed in the fuselage. As mentioned earlier, the numerical approach has been utilized as a selection tool for choosing the best air-intake configuration. So, Fig. 21 illustrate the comparison of the air-intake efficiency for each configuration tested by considering both AOA $(\alpha=2$, cruise condition and $\alpha=15$, takeoff). Both elliptic and circular air intakes have shown efficiencies over $80 \%$ and are quite desirable for engine cooling, albeit additional evaluation for the drag penalty must be considered.

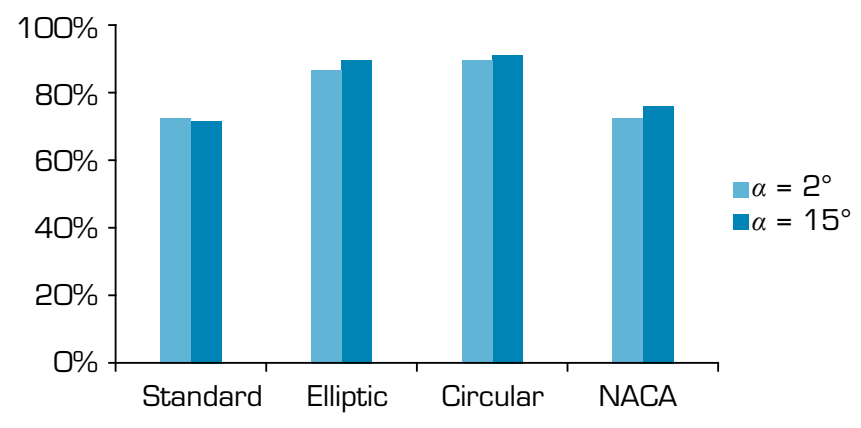

Figure 21. Efficiency comparison of air intake. 


\section{Drag penalty}

The evaluation of drag of air intakes by CFD is not a straightforward process because of its complicated geometry and the extension of the entrance duct inside the fuselage. Additionally, the computation of drag by itself is dependent of mesh refinement, upcoming boundary layer description and discretization of geometry. For such class of problem, the skin-friction evaluation is substantial for given a reasonable value of drag coefficients. Even though the mesh generation was taken carefully through this work, as previous mentioned, it could be biased to affirm that the results are accurate in terms of absolute values of drag coefficient (Cd). Therefore, the values of Cd will not be present but the DCd between the configurations. Also, it is important to mention that the fuselage drag is not considered, being the values of the intake drag evaluated separately. To achieve such task, the Cd value calculation was parametrized by considering an averaged value for the projected inlet area of the four intakes as $0.0137 \mathrm{~m}^{2}$. Figure 22 shows the proportional drag between the intakes simulated, considering that the highest drag coefficient is provided by the standard air intake.

From Fig. 22, it can be concluded that, despite NACA intake does not show the best intake efficiency, it produces much less drag than the others intakes.

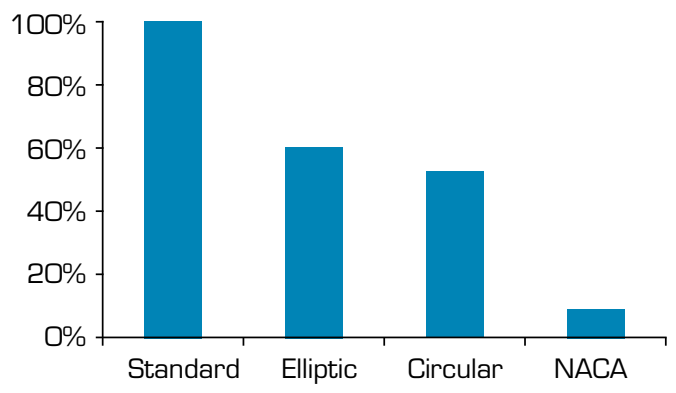

Figure 22. Proportional drag (DCd) among the air intakes.

\section{Design selection}

As an industrial application, the design selection for the air intake to be installed on Bumerangue EX-27 has been taken into consideration, besides the parameters studied herein, other variables such as cost for implementation, availability of machinery tools to manufacture, aesthetics when installed in the airplane. Other issues regarding loads and integration of materials are also important, but they were not considered in this approach. In a list of priority, the drag penalty is the most important parameter to be considered, followed by the efficiency and aesthetics. However, drag could be augmented if the efficiency is low inside the flight envelop. Considering these facts, it is tendentious to choose the NACA air intake. Based on the results, the NACA air intake has provided a low drag penalty and a reasonable $70 \%$ of ram air recovery for the conditions analyzed. However, due to the size of the NACA air intake and the impact in the surface area in the rear cabin of the airplane plus the aesthetics that could compromise the design, the NACA air intake was not considered as a final selection. Elliptic and circular scoops are good options for the airplane since they provide a reasonable compromise between drag and efficiency.

In the final assembly line for this aircraft, both elliptic and circular scoops could be implemented. Figure 23 describes one of these configurations. The scoop air intake achieves the initial proposal of engine cooling, the focus of this investigation.

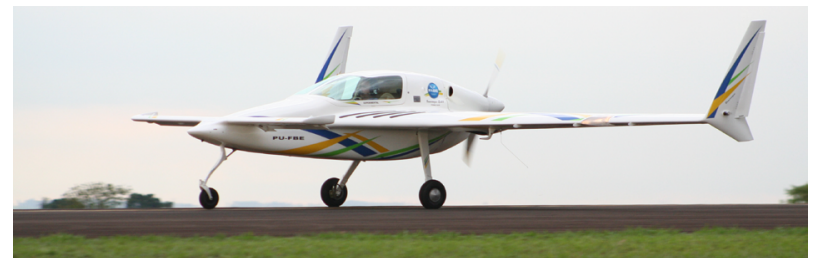

Figure 23. Canard aircraft with semicircular scoop (Courtesy FABE Ltd.). 


\section{CONCLUSIONS}

A numerical investigation of the flow over different air intakes was carried out with the main purpose of implementing the best configuration in a canard-type aircraft for engine cooling. In such aircraft design, the need for engine cooling is a very important aspect since the engine is placed at the back portion of the fuselage.

This work described a semiempirical approach coupled with CFD simulations to design and select an air intake that will suit this target at different angle-of-attack flight conditions. A set of numerical studies were performed with four air intakes installed in the aircraft fuselage, a NACA-type and three variations of scoop intakes. From the numerical computations, it was concluded that the air flow could change over the region of the air intake due to change in the AOA. Also, the intake efficiency varied from $63 \%$ up to $85 \%$ with the highest values for the elliptic and circular scoops at $\mathrm{AOA} 15^{\circ}$ (take-off condition).

Flow visualization results have also shown that the aircraft geometry, as a canard airplane with front-wing (stabilizer), has great influence in the flow over the last portion of the fuselage, influencing the air intakes at that location. In terms of drag penalty, it was confirmed that the NACA air intake has the lower impact, but it was not selected to be installed in the aircraft due to its final size needed to promote all the mass flow rate to cool the engine compartment. Due to this restriction, the installation of a scoop was the option, at the price of increasing the aerodynamic drag of the whole aircraft. Both circular and elliptic scoops could be implemented in this aircraft-configuration with a reasonable compromise between ram recovery ratio and drag penalty.

This study also indicates that the procedure used in this work is acceptable as an engineering tool, with relatively low cost, for design selection and indicative of design trends. Further work may also apply to improve the aircraft configuration such as the flight test with the selected air intake properly instrumented for measurements of pressure as well as flow visualization at the region of the air intakes. Another possibility is to test different air intakes in a wind tunnel to provide detailed data, under controlled situation, for validation and improvement of the numerical CFD setup. Also, it has been requested to test an alternative air intake under the wing close to the fuselage intersection, which could help the airplane aesthetics by avoiding the assembly of the scoop in the clean end part of the fuselage (over the wing).

\section{AUTHOR'S CONTRIBUTION}

Conceptualization: Almeida O; Methodology: Almeida O, Souza PC and Cunha E; Investigation: Almeida O and Souza PC; Writing - original draft: Almeida O; Writing -review \& editing: Almeida O; Funding acquisition: Almeida O; Resources: Almeida O; Supervision: Almeida O.

\section{DATA AVAILABILITY STATEMENT}

The data that support the findings of this study are available from Fábrica Brasileira de Aeronaves (FABE), but restrictions apply to the availability of these data, which were used under license for the current study, and so are not publicly available. Data are however available from the authors upon reasonable request and with permission of FABE.

\section{FUNDING}

Fábrica Brasileira de Aeronaves Ltd. 


\section{ACKNOWLEDGEMENTS}

The authors acknowledge with gratitude the support of CPAERO - Experimental Aerodynamics Research Center at Federal University of Uberlândia for carrying out this work. Finally, we would like to thank the collaboration with the Brazilian Aircraft Factory (FABE).

\section{REFERENCES}

[ESDU] Engineering Sciences Data Unit (2004) ESDU 86002, - Drag and pressure recovery characteristics of auxiliary air inlets at subsonic speeds. London: Engineering Sciences Data Unit (ESDU).

Almeida O, Souza PRC (2017) Flow characterization from a NACA air intake assembled in a canard type aircraft. RETERM 16(1):3-10. https://doi.org/10.5380/reterm.v16i1.62183

Chitale KC, Rasquin M, Sahni O, Shephard MS, Jansen KE (2014) Boundary layer adaptivity for incompressible turbulent flows. Paper presented 11th World Congress on Computational Mechanics (WCCM XI). WCCM; Barcelona, Spain. [accessed May 24 2020]. https://arxiv.org/abs/1405.0620

El-Sayed AF, Emeara MS (2016) Aero-engines intake: a review and case study. J Robot Mech Eng Resr 1(3):35-42. https://doi. org/10.24218/jrmer.2016.15

Faria WN, Oliveira GL (2002) Análise de entradas de ar tipo NACA com gerador de vórtices. Paper presented 9th Brazilian Congress of Thermal Engineering and Sciences-ENCIT 2002. ENCIT; Caxambu, Minas Gerais, Brazil.

Frick CW, Davis WF, Randall LM, Mossman EA (1945) An experimental investigation of NACA submerged-duct entrances. aircraft design, testing and performance. NACA-ACR-5I20. [accessed May 24 2020]. https://ntrs.nasa.gov/citations/20050061115

Jongen T (1992) Simulation and modeling of turbulent incompressible flows (PhD thesis). Lausanne: EPF Lausanne, Lausanne. In English.

Knopp T (2006) On grid-independence of RANS predictions for aerodynamic flows using model-consistent universal wall-functions. Paper presented ECCOMAS CFD 2006: Proceedings of the European Conference on Computational Fluid Dynamics. ECCOMAS; Egmond aan Zee, Netherlands. [accessed May 18 2020]. http://resolver.tudelft.nl/uuid:10c7d97710c4-4296-a586-e68492643039

Koch S, Rütten M, Rein M (2015) Experimental and numerical investigations on integrated intakes for agile and highly swept aircraft configurations. Paper presented Deutscher Luft- und Raumfahrtkongress 2015. Göttingen, Germany. [accessed March 05 2018]. https://www.dglr.de/publikationen/2015/370173.pdf

Laruelle G (2002) Air Intakes: Role, Constraints and Design. Paper presented 23rd Congress of International Council of the Aeronautical Sciences. ICAS; Toronto, Canada. [accessed March 05 2018]. https://www.icas.org/ICAS_ARCHIVE/ ICAS2002/ABSTRACTS/643.HTM

Liu H-J, Su C-C, Huang S-L (2013) A study on the engine compartment airflow of a light aircraft using computational fluid dynamics. Trans Can Soc Mech Eng 37(3):641-653. https://doi.org/10.1139/tcsme-2013-0052

Menter FR (1993) Zonal two equation k- $\omega$ turbulence models for aerodynamic flows. Paper presented AIAA 23rd Fluid Dynamics, Plasmadynamics, and Lasers Conference. AIAA; Orlando, Florida, United States. https://doi.org/10.2514/6.1993-2906 
Menter FR (1994) Two-Equation Eddy-Viscosity Turbulence Models for Engineering Applications. AIAA J (32)8:1598-1605. https://doi.org/10.2514/3.12149

Metacomp Technologies (2014) Metacomp CFD++ version 14.1.1. [accessed Jan 22 2018] http://metacomptech.com

Pignier NJ, O’Reilly CJ, Boij S (2016) Aerodynamic and aeroacoustic analysis of a submerged air inlet in a low-Mach-number flow. Comput Fluids 133:15-31. https://doi.org/10.1016/j.compfluid.2016.04.010

Rütten M, Krenkel L, Freund M (2009) Parametric design, comparison and evaluation of air intake types for bleedless aircraft. Paper presented 39th AIAA Fluid Dynamics Conference. AIAA; San Antonio, Texas, United States. https://doi. org/10.2514/6.2009-3902

Rütten M, Kuckenburg S, Koch S, Rein M (2013) Investigation of the flow within partially submerged scoop type air intakes. Paper presented 31st AIAA Applied Aerodynamics Conference. AIAA; San Diego, California, United States. https://doi. org/10.2514/6.2013-2912

Seddon J, Goldsmith EL (1999) Intake aerodynamics. Oxford: Blackwell Science.

Shams TA, Masud J (2015) Steady analysis of NACA flush inlet at high subsonic and supersonic speeds. Paper presented Proceedings of the World Congress on Engineering 2015 Vol II. WCE; London, United Kingdom.

Silveira BH, Souza PRC, Almeida O (2017) Numerical investigation of a NACA air intake for a canard type aircraft, IJAERS 4(5):32-40. https://doi.org/10.22161/ijaers.4.5.7

Stalewski W, Żółtak J (2014) The preliminary design of the air-intake system and the nacelle in the small aircraft-engine integration process. Aircr Eng Aerosp Technol 86(3):250-258. https://doi.org/10.1108/AEAT-01-2013-0015

Taskinoglu E, Knight D (2003) Design optimization for submerged inlets - Part I. Paper presented 41st Aerospace Sciences Meeting and Exhibit. AIAA; Reno, Nevada, United States. https://doi.org/10.2514/6.2003-1247

Wilcox DC (1998) Turbulence modeling for CFD. La Cañada: DCW Industries. Chapter 5, Effects of Compressibility; p. $172-180$. 